\title{
Proposições conceituais em torno da formação e do trabalho docente: uma orientação emancipatória para o desenvolvimento profissional
}

\author{
Maria Isabel de Almeida ${ }^{1}$ \\ Tiago Rufino Fernandes ${ }^{2}$
}

\begin{abstract}
RESUMO
Com base em pesquisa que investigou possibilidades para o desenvolvimento profissional de professores em um curso de formação, defende-se uma articulação entre os conceitos de desenvolvimento profissional, formação continuada e trabalho docente como quadro referencial para pesquisas sobre formação. Tomando como referências centrais autores como Marx (2013), Nóvoa (1995, 2000, 2009), García (2003, 2009), Almeida (1999) e Contreras (2012), após realizar uma revisão da produção bibliográfica sobre o tema da formação de professores, apresentam-se algumas linhas de força da articulação conceitual pretendida. O objetivo é oferecer um conjunto de orientações e princípios teórico-conceituais para a abordagem dos temas que se referem ao desenvolvimento profissional docente com orientação emancipatória.
\end{abstract}

PALAVRAS-CHAVE: Desenvolvimento Profissional. Trabalho Docente. Formação Continuada. Emancipação.

Conceptual propositions articulations around teachers' education and teaching work: an emancipatory orientation for professional development

\section{ABSTRACT}

\footnotetext{
${ }^{1}$ Doutora em Educação. Professora Associada Sênior da Faculdade de Educação da Universidade de São Paulo, São Paulo, Brasil. https://orcid.org/0000-0003-2506-2972. mialmei@usp.br.

${ }^{2}$ Doutorando em Educação pela Universidade de São Paulo. Professor da Rede Municipal de Educação do Município de Guarulhos, Guarulhos, São Paulo, Brasil. https://orcid.org/0000-0002-3929-3125.tiago_rufino@yahoo.com.br.
} 
Based on a research that investigated possibilities for the professional development of teachers in a formation course, it is advocated an articulation between the concepts of professional development, continuing education and teaching work as reference for research on teachers' education. Taking as central references authors such as Marx (2013), Nóvoa (1995, 2000, 2009), García (2003, 2009), Almeida (1999) and Contreras (2012), after reviewing bibliographic production on the teachers' education, we present some lines of strength of the intended conceptual articulation. The objective is to offer a set of orientations and theoretical-conceptual principles to approach the themes that refer to the professional development of teachers with emancipatory orientation.

KEYWORDS: Professional Development. Teaching Work. Continuing Education. Emancipation.

\section{Introdução}

Com base em nossa pesquisa de $\mathrm{Mestrado}^{3}$, na qual investigamos o desenvolvimento profissional de professores da Educação de Jovens e Adultos (EJA) com base em um curso de formação continuada, pretendemos apresentar uma contribuição conceitual ao desenvolvimento de pesquisas sobre o campo da formação de professores em suas relações com o trabalho realizado pelos docentes na escola pública.

Intitulada Desenvolvimento profissional de professores da escola pública: uma análise do curso Estudo do Meio na Educação de Jovens e Adultos, a pesquisa intencionou adentrar o campo da formação continuada localizando-a no contínuo do desenvolvimento profissional docente, tendo como referência o materialismo histórico-dialético e o trabalho como centro da constituição identitária do ser humano.

\footnotetext{
${ }^{3}$ Desenvolvimento profissional de professores da escola pública: uma análise do curso Estudo do Meio na Educação de Jovens e Adultos, Faculdade de Educação da Universidade de São Paulo - 2018, sob orientação da Profa. Dra. Maria Isabel de Almeida. Disponível em: <http://www.teses.usp.br/teses/disponiveis/48/48134/tde-14122018101307/pt-br.php>.
} 
A pesquisa teve como sujeitos professores da EJA da cidade de Guarulhos, situada na Região Metropolitana de São Paulo, e foi desenvolvida mediante as técnicas de análise dos documentos referentes à curso Estudo do Meio durante os anos de sua realização, entre 2002 e 2008, e entrevistas semiestruturadas com quatro participantes: três professores e uma funcionária em função técnica na Secretaria Municipal de Educação. A referência epistemológica da pesquisa foi dialética e operou segundo uma relação dinâmica entre o singular (o curso de formação), o particular (o contexto da Rede Municipal) e o universal (a totalidade social), buscando perceber as conexões que os fenômenos singulares estabelecem com os elementos mais amplos do campo da formação de professores, como também da política educacional.

Os autores fundamentais do estudo foram, entre outros, Kosik (1969), Marx (2013), Nóvoa (1995), García (2003, 2009), Contreras (2012) e Almeida (1999). Foi em diálogo com tais autores e com os sujeitos da pesquisa, bem como com o contexto fornecido pelos documentos, que construímos o quadro referencial teórico a partir do qual orientamos a construção argumentativa. É fundamental destacar, ao apresentar o substrato teórico da pesquisa, o caráter situado e contextualizado da contribuição aqui pretendida, pois nossa argumentação se constrói na consideração dos contextos micro e macroestruturais que determinam a ação e a prática docente. Em outras palavras, não desconhecemos a importância das condições de trabalho e da carreira docente como condições centrais para que a formação possa se efetivar. Nesse sentido, afastamo-nos de um paradigma de teoria pura ou de empiria pura, mas produzimos teoria como diálogo com os sujeitos e com as práticas em um movimento dialético.

O Estudo do Meio é uma metodologia interdisciplinar de análise do contexto e da realidade local ${ }^{4}$ com o objetivo de investigar seus problemas e suas implicações na vida dos sujeitos participantes. Como proposta de

\footnotetext{
${ }^{4}$ Mais precisamente de um meio rural ou urbano. A realidade local a que nos referimos corresponde ao caráter que o Estudo do Meio assumiu na Rede Municipal de Educação de Guarulhos.
} 
formação, visa aproximar a escola do seu entorno, refletindo em seu interior sobre questões sociais, ambientais, históricas, entre outras, buscando contribuir para superação da fragmentação curricular em direção à interdisciplinaridade no trabalho com o conhecimento na escola. O curso, inserido no Programa de Formação Permanente do município de Guarulhos, procurou contribuir para o processo formativo de professores e para a ressignificação do olhar sobre a cidade.

Portanto, em resumo, o que propomos neste artigo é uma articulação conceitual que se apresenta como um quadro referencial. As categorias do esquema proposto são o desenvolvimento profissional, a formação continuada e o trabalho docente. É em tal perspectiva que nossa pesquisa, ao mesmo tempo que investiga uma ação localizada em um tempo e um espaço dados, também propõe uma articulação conceitual cuja relevância está no esforço de ressignificação da compreensão sobre o desenvolvimento profissional docente.

\section{Panorama das pesquisas sobre formação docente: em busca de coordenadas}

Ao longo da investigação, ao realizar o balanço bibliográfico das produções realizadas, nosso objetivo foi dialogar com as fontes consultadas para levantar as coordenadas que configuraram o campo da formação de professores no Brasil. Diante disso, o primeiro aspecto que salientamos é o de que, não obstante sua crescente consolidação, ainda estamos distantes de um delineamento de todo claro do que se vem denominando formação de professores (FCC, [s. d.], p. 94).

Todavia, em termos conceituais, as linhas atuais de investigação vêm concebendo a formação de professores como um continuum (BRZEZINSKI, 2006; DINIZ-PEREIRA, 2010), em que formação inicial e continuada são momentos de um processo mais amplo de desenvolvimento profissional 
docente. No entanto, destacamos que a revalorização da formação de professores, acompanhada da emergência da formação continuada, corresponde a uma tendência mundial no bojo dos organismos internacionais e de sua preocupação com o papel da educação na economia e no desenvolvimento.

Nos últimos anos, muitos estudos e debates emergiram no Brasil iluminando o campo da formação de professores. A partir da década de 1990, termos como desenvolvimento profissional, formação inicial e contínua, professor reflexivo, entre outros, penetraram as elaborações teóricas na educação, renovando as categorias conceituais com que o campo se desenvolveu. Poderíamos dizer que esse campo ganhou uma nova significação com a afluência, entre nós, de um conjunto de autores que renovaram compreensões e abordagens sobre as questões que envolvem o trabalho docente e a preparação adequada desse profissional (NÓVOA, 1995, 2000; SCHÖN, 1995; TARDIF, 2002; ALARCÃO, 2003).

Esse campo se renova não só com a leitura massiva de autores estrangeiros, mas também pela produção de conhecimento sobre o tema em nível de pós-graduação stricto sensu. Tivemos crescimento em volume de pesquisas que veio acompanhado de uma pluralidade de abordagens.

Se olharmos o desenvolvimento histórico dos estudos sobre formação de professores, podemos constatar algumas prioridades no que se refere ao desenvolvimento profissional, o trabalho docente e a formação continuada (BRZEZINSKI, 2006; ANDRÉ, 2002). Ao tomarmos o período que vai da redemocratização do país e a configuração do campo da formação de professores, a década de 1980 pode ser considerada importante para a emergência dos estudos críticos sobre o tema ${ }^{5}$. No entanto, é na década de 1990 que a produção científica nos programas de pós-graduação cresce em quantidade, embora os estudos sobre formação de professores tenham se

\footnotetext{
5 Tanuri (2000), referindo-se à formação de professores dos anos iniciais do Ensino Fundamental, situa a intensificação do debate na década de 1980 com a revitalização de projetos de formação docente em nível normal e universitário.
} 
mantido estáveis, entre $5 \%$ e $7 \%$ da produção total do período que vai de 1990 a 1996 (ANDRÉ, 2002, p. 9).

Não obstante, são produzidos no período citato 284 trabalhos, o que também revela o interesse dos pesquisadores em nível de pós-graduação na miríade de temas que se identificam com o espectro da formação de professores. Segundo levantamento de André (2002), ao analisar os resumos de teses e dissertações, artigos de periódicos nacionais e trabalhos apresentados no Grupo de Trabalho de Formação de Professores da Associação Nacional de Pós-Graduação e Pesquisa em Educação (ANPEd), no período que vai de 1990 a 1998, percebe-se recorrência de alguns temas que marcaram as pesquisas sobre a formação de professores. Os que se mostram como grandes categorias, segundo a autora, são os ligados à formação inicial, à formação continuada e à identidade e profissionalização (ANDRÉ, 2002, p. 19).

No período posterior, mais precisamente entre 1997 e 2002, o panorama dos estudos sobre formação de professores se amplia qualitativa e quantitativamente (BRZEZINSKI, 2006, p. 12). No estado da arte realizado a partir de produções discentes dos programas de Mestrado e Doutorado no Brasil, sete categorias foram percebidas da análise e revelam a tendência investigativa nesse período: a) concepções de docência e de formação de professores; b) políticas e propostas de formação de professores; c) formação inicial; d) formação continuada; e) trabalho docente; f) identidade e profissionalização docente; g) revisão de literatura (BRZEZINSKI, 2006, p. 17). Nesse levantamento, alguns temas apresentam importantes interseç̧ões, como o trabalho docente e a identidade, assim como o continuum (desenvolvimento profissional) entre formação inicial e continuada.

No período de 2003 a 2010, novamente com a tentativa de um balanço crítico das produções, Brzezinski (2014) aponta a ampliação do número de pesquisas, o que torna complexo o balanço. A autora, ao apresentar a parte metodológica do estudo, mostra como a dinâmica das produções nesse 
período contribui para a emergência de novas categorias, tornando mais abrangente a classificação dos estudos. É o que se verifica com o tema da formação continuada (BRZEZINSKI, 2014, p. 19):

O entendimento e a extensão do campo do que hoje se chama no Brasil de "formação continuada" antes era denominado de "educação permanente", e a "prática docente" ou a "prática pedagógica" passaram a ter uma concepção mais abrangente das ações do professor, com o conceito de "trabalho docente". Outra expressão, ainda bastante utilizada, mas que vem, paulatinamente, se alterando é "a articulação entre formação inicial e continuada" por "desenvolvimento profissional", sobre a justificativa de que a formação se dá ao longo da vida (GARCÍA, 2009, apud BRZEZINSKI, 2014, p. 19).

De acordo com a citação, nossa investigação se situa no panorama dessa "nova" terminologia que surge para pensar a formação dos professores. Pensamos que esse novo vocabulário, o qual introduz temáticas diversificadas, é reflexo de um desenvolvimento do campo da formação de professores para pensar a complexidade de seu objeto. Isso mostra as interfaces que os conceitos e temas estabelecem entre si, pois permitem a articulação, por exemplo, do desenvolvimento profissional com o trabalho docente.

Voltando aos estudos, as categorias de organização para o período de 2003 a 2010 permanecem as mesmas do período de 1997 a 2002, mas destacamos o relevo e a maior expressão que as categorias de desenvolvimento profissional e trabalho docente têm ganhado, levantandose, com efeito, o desafio de um esforço conceitual em relação a como são tomadas nas pesquisas e que contribuições podem fornecer às análises. Devemos notar, no entanto, que, no período de 2003 a 2010, identifica-se diminuição do interesse pelo tema da formação continuada entre mestrandos e doutorandos, sendo 14\% de 574 trabalhos entre 2003 e 2007, e 
$12 \%$ das 200 pesquisas identificadas no período de 2008 a 2010 (BRZEZINSKI, 2014, p. 116).

Ainda no âmbito do balanço, mas focando nas pesquisas em nível de pós-graduação, é possível realizar uma ampliação do diagnóstico oferecido pelos estados da arte anteriores para situar em linhas gerais o estado das pesquisas sobre desenvolvimento profissional docente no período de 2011 a 2015. Com o objetivo de levantar tendências investigativas, procuramos nestas breves páginas cobrir o panorama da formação de professores de 1990 a 2015, considerando os recortes desses estudos no que se refere aos interesses de nossa pesquisa.

De modo geral, verificamos que a produção de conhecimento no campo da formação de professores realizada nos programas de Mestrado e Doutorado do país, entre 2011 e 2015, é marcada por um grande número de trabalhos e por uma acentuada diversidade de temas. Um levantamento no Banco de Teses da Coordenação de Aperfeiçoamento de Pessoal de Nível Superior (CAPES), considerando o período supracitado, mostra que o tema da formação tem sido largamente estudado nos últimos anos, revelando um campo em expansão, mas que também pode estar a sofrer uma dispersão pela abrangência dos problemas que o envolvem. Desse levantamento, conduzido segundo os descritores desenvolvimento profissional, profissionalidade docente e identidade docente, encontramos o total de teses e dissertações no número de 182 registros, o que revela a grande produção acadêmica nesse campo em nosso país. Desse número, 60 são teses e 122 são dissertações, produzidas em todas as regiões do Brasil, com destaque para a região Sudeste e Sul, com 77 e 46 produções respectivamente.

Outro levantamento por nós realizado no Banco de Teses da CAPES, com o mesmo período de 2011 a 2015, agora com os descritores formação contínua de professores e políticas de formação de professores, confirma o interesse pelo tema do desenvolvimento profissional, bem como uma provável pluridirecionalidade das pesquisas. O número total de trabalhos soma a 302 registros, dos quais 69 são de Doutorado e 233, de Mestrado. 
Novamente nesse período a região Sudeste se apresenta como o centro de maior produção de pesquisas, com 127 trabalhos, seguida da região Sul, com 87 trabalhos, confirmando uma tendência já verificada em outros campos relativamente ao destaque do Sul/Sudeste do Brasil na produção do conhecimento em Educação no país.

As pesquisas também se debruçam sobre diferentes recortes, variando da análise de programas de formação continuada a temas que se conectam com reflexões sobre currículo, história da formação docente e educação a distância, por exemplo, verificados também pelas palavras-chave de cada trabalho.

Por outro lado, a recorrência a termos como profissionalização, desenvolvimento profissional e formação continuada atesta a existência de eixos importantes sobre os quais produzir as pesquisas. É nesse contexto que propomos uma formulação das categorias centrais de nosso trabalho, com o fim de construir um quadro referencial teórico consistente para a análise do desenvolvimento profissional dos professores no âmbito da formação continuada.

\section{A emancipação em questão: parâmetro "normativo" para o desenvolvimento profissional}

A primeira observação que fazemos neste momento é a de que emancipação é um conceituo irredutível, no sentido de que ele é polissêmico em sua história e indica a pluralidade dos projetos sociais em disputa. Em sentido histórico-filosófico, Melo (2009) argumenta sobre as mudanças dos sentidos da emancipação conforme os paradigmas que a estruturaram desde o século XIX. Procurando superar a antinomia entre reforma e revolução, o autor analisa a evolução do conceito desde o que chama de paradigma produtivista até chegar à noção de emancipação relacionada à democracia radical, recolocando as formas de sua interpretação no interior da política, 
do direito e do reconhecimento. A polissemia do conceito é expressão de sua importância, mas também de sua plasticidade para pensar diferentes orientações de transformação social ou da esfera pública, o que nos leva a falar em processos, possibilidades ou potenciais emancipatórios.

Tal como exposto pelo autor, partimos de uma abertura em relação à recepção dos textos de Marx e do marxismo, estruturantes de nosso conceito de trabalho, para pensar os problemas contemporâneos, distanciando-nos dos dogmatismos que obliteram a análise em receituários interpretativos fixos, considerando que "a indagação pela emancipação não nasce em si mesma em razão da teoria, pois já está presente na dinâmica efetiva dos conflitos. Mas a compreensão de suas diferentes formas de manifestação na teoria e na prática nos impele à reconstrução de seus sentidos, assim como a justifica" (MELO, 2009, p. 208).

Por isso, para nossa pesquisa, a emancipação se liga a dois elementos de justificação social e epistemológica: por um lado, implica a luta pelo reconhecimento socioprofissional dos professores e, por outro, pressupõe a formação de uma posição de sujeito erigida pela construção de um lugar de fala docente.

Nessa propositura, o conceito de desenvolvimento profissional também se apresenta no contexto da polissemia e constitui uma categoria de análise importante para a reflexão sobre a vida e a trajetória dos professores. Há diversos autores que se dedicam ao seu estudo, cada um, por sua vez, trazendo uma nuança específica ao tratamento da questão de como o professor constitui sua relação com o trabalho que realiza e como constrói as competências necessárias ao ensino (MORGADO, 2011; IMBERNÓN, 2004; DAY, 2001; NÓVOA, 1995，1999，2009; GARCÍA, 2003，2009; ALMEIDA, 1999; AZZI, 2009; FUSARI, 1997; LIMA, 2001).

Falar em desenvolvimento profissional inicialmente traz uma contribuição importante porque permite conceber o tornar-se professor como um processo que não se encerra na formação inicial e nos primeiros anos de socialização junto aos pares. Como processo, ele precisa ser visto dentro de 
uma perspectiva de socialização profissional que envolve os saberes docentes, as escolas, as políticas públicas e a construção das identidades profissionais.

Como apontamos brevemente no balanço das produções, o desenvolvimento profissional se tornou um objeto de preocupação por aqueles que se dedicam à formação inicial e continuada de professores. Todavia, o delineamento de uma visão emancipatória desse conceito, calcada em uma visão histórico-dialética, embora já tenha encontrado elaborações importantes e centrais (AZZI, 2009; LIMA, 2001), ainda está marcado por um referente que não explicita o papel radicalmente transformador da escola em sua relação com a sociedade. Buscamos, por nosso turno, pensar um desenvolvimento profissional docente como chave dos processos de transformação da educação, de protagonismo docente e criticamente comprometido com a educação pública.

Com isso, busca-se a autonomia dos professores entendida como um conceito multidimensional, que inclui a reivindicação trabalhista, o distanciamento crítico e as relações profissionais (CONTRERAS, 2012). A autonomia expressa a assunção do papel do sujeito como autor de sua prática, como alguém capaz de refletir sobre a ação, planejá-la e assumir posições e compromissos com processos de mudança.

Poderíamos dizer que o desenvolvimento profissional com orientação emancipatória deveria buscar graus progressivos de autonomia dos professores como forma de superar a precarização de seu trabalho e sua alienação. Nessa perspectiva, o referencial crítico da emancipação só pode ser concebido adequadamente quando a produção do conhecimento está comprometida com a transformação de um estado de coisas. Logo, o que se busca em uma orientação emancipatória para o desenvolvimento profissional docente é informar uma práxis crítica e reflexiva que tem no ensino, como prática concretamente situada, um de seus modos de realização. E nesse sentido é fundamental pensar criticamente a relação entre a formação continuada dos docentes e as condições em que seu 
trabalho se realiza. Se assim não ocorre, no plano das ações levadas a cabo pelos sistemas de ensino, observamos, entre outras coisas, a já conhecida distância entre o que se "aprende" na formação e o que ocorre nas escolas.

O conceito de desenvolvimento profissional é tomado, pois, em um amplo delineamento para abarcar a complexidade do processo de tornar-se professor, articulando em seu interior uma série de dimensões, como a trajetória e a identidade docente, as instâncias institucionais e os saberes. Como categoria que abarca a constituição social do ser professor, o desenvolvimento profissional se apresenta como chave de interpretação, um dispositivo conceitual que permite aberturas para compreender a relação dos professores com seu trabalho.

Nesse diapasão, esse conceito só pode ser devidamente compreendido se tiver em sua base o trabalho docente, o tipo específico de atividade que o professor desenvolve (o ensino), e como, por ela, ele constrói sua identidade e seu olhar para a profissão. A categoria trabalho se apresenta organicamente interseccionada ao conceito de desenvolvimento profissional. Assim, relacionado ao conceito de formação continuada, organizamos a estrutura analítica apresentada em nossa pesquisa:

DIAGRAMA 1 - Intersecção de categorias no contexto da pesquisa

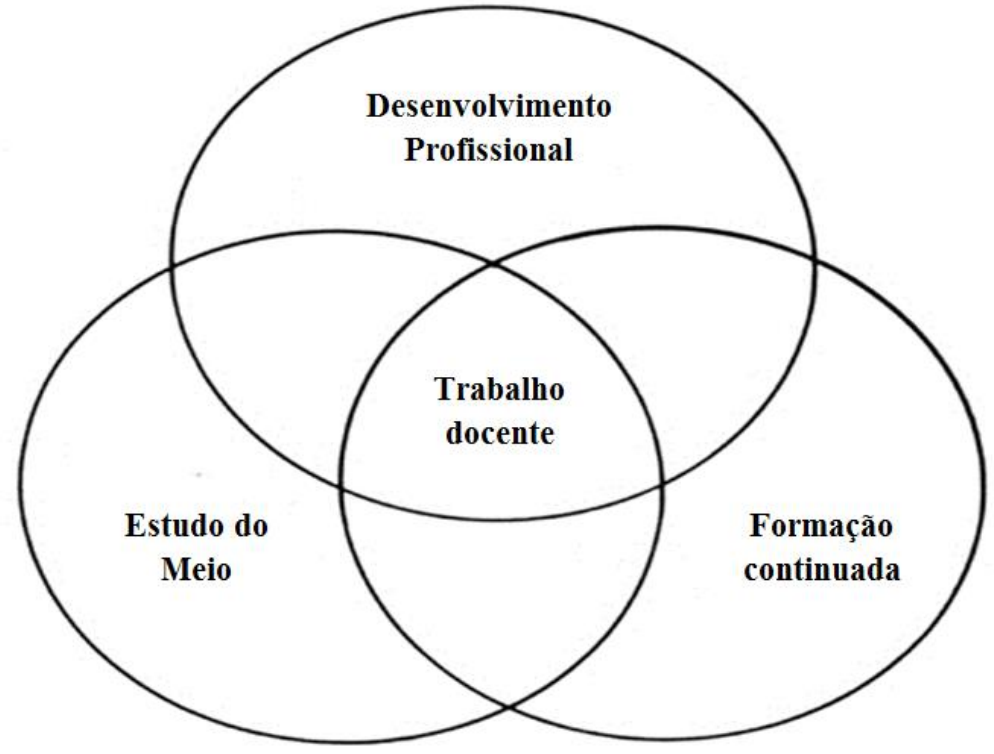

Fonte: Autores 
Pelo que se apresenta, o trabalho docente está no centro de uma complexa intersecção entre a formação continuada, as modalidades de formação - no caso de nossa pesquisa, o Estudo do Meio - e o desenvolvimento profissional. Toda ação que visa a contribuir para o desenvolvimento profissional dos professores precisa não só considerar as referidas intersecções, mas ter como referência o trabalho concretamente realizado pelos professores. A formação, assim, é fundamentalmente marcada pelas situações particulares da prática, suas contradições e tensões.

É com esse referencial, que atribui à prática uma posição central, que o processo reflexivo pode ganhar densidade no contexto da formação docente, estruturada como lugar em que os professores refletem sobre seus saberes e a natureza de seu trabalho. Diante disso, poderíamos dizer que a ação de formação continuada de desenvolvimento profissional dos professores da escola pública só pode se constituir como tal se tiver como base o trabalho docente concretamente situado no espaço e no tempo onde está sendo realizado.

\section{Desenvolvimento profissional: diálogo com autores e esforço de proposição}

Para propor a formulação das bases do conceito de desenvolvimento profissional, dividimos nossa argumentação em dois momentos. Partindo de García (2009), estabelecemos as tendências investigativas atuais do tema e, em seguida, apresentamos delineamentos mais precisos do conceito, que explicitam a maneira como o tomamos para, por fim, apresentar uma caracterização conceitual de como tomamos o desenvolvimento profissional.

Em texto publicado em 2009, intitulado Desenvolvimento Profissional Docente: passado e futuro, Carlos Marcelo García atualiza o panorama de 
discussões sobre o desenvolvimento profissional com base, sobretudo, em uma tradição anglófona, na qual o conceito tem sido estudado como preocupação central no contexto das políticas educacionais. Partindo de uma leitura das revisões bibliográficas, o autor defende ser possível fornecer uma resposta à pergunta “como se aprende a ensinar?” (GARCÍA, 2009).

Para García, o conceito de desenvolvimento profissional é o que melhor expressa a noção de professor como profissional do ensino, o que coloca a natureza do trabalho docente como eminentemente voltado para certa especificidade. Se por ensino entendermos "uma prática social complexa" (PIMENTA, 2016), o desenvolvimento profissional pode fornecer pistas para pensarmos a prática docente em sua relação com os valores e as visões sociais historicamente em disputa.

Nesse ponto, podemos fazer referência a Roldão (2007) quando se dedica à especificidade da atuação docente. Para ela, o que distingue os professores de outros profissionais é a especificidade do ensinar, organizado segundo quatro dispositivos, a saber, a natureza compósita do conhecimento docente, a capacidade analítica, a natureza interrogativa e mobilizadora própria de seu conhecimento profissional e a meta-análise (distanciamento e autocrítica) (ROLDÃO, 2007).

A articulação desses "dispositivos geradores de especificidade" tem implicações na forma como se compreende o ensino, posto que altera a compreensão tanto dos saberes necessários para o ensino quanto daquilo que se espera na mobilização das aprendizagens nos contextos de vida. Uma aprendizagem da docência que não considere as dimensões específicas do ensino, reduzindo-o a mero manejo técnico de metodologias, produz nos futuros professores a perda da capacidade de pensar o seu trabalho, assumilo criticamente e, por isso, os distancia de uma orientação emancipatória. A indagação de Pimenta (2009) nos ajuda a refletir sobre esse aspecto:

Que professor se faz necessário para as necessidades formativas em uma escola que colabore para os processos emancipatórios da população? Que opere o ensino no sentido de incorporar as 
crianças e os jovens no processo civilizatório com seus avanços e seus problemas? (PIMENTA, 2009, p. 19).

Um aspecto que se depreende do texto de García (2009) é a relação entre o desenvolvimento profissional e as aprendizagens docentes. Se as noções do que chamamos ensino e aprendizagem se alteram, é esperado que a formação do profissional do ensino também sofra alterações em termos daquilo que dele se espera socialmente. O professor, como sujeito social, também aprende em diferentes lugares e instâncias, seja nos espaços formais e institucionais, seja em experiências não formais (ALMEIDA, 1999), mas cujo centro de concretização é o trabalho que realiza. Este ainda continua possuindo uma centralidade para pensarmos o ser social e profissional dos professores.

Essa natureza processual do desenvolvimento profissional, bem como sua constituição em diferentes instâncias, já havia sido identificada, para o caso brasileiro, por Almeida em 1999, o que marca uma linha de continuidade nas preocupações em relação a esse conceito e à maneira como ele vem sendo compreendido no campo educacional. A amplitude que envolve o desenvolvimento profissional nos faz concebê-lo a partir da relação dos próprios professores com vivências de várias ordens, em uma situação de aprendizagem contínua ao longo da vida, o que nos provoca à realização de uma cartografia móvel dos espaços de formação de professores, os quais constroem territórios de produção de si enquanto sujeito e profissional do ensino. Quando se pensa a profissão do professor, o que está implicado é a sua pessoa tal como se projeta em seu trabalho. Esse é o elemento fundante do ser social docente, e uma ação que visa contribuir para seu crescimento profissional precisa necessariamente considerar os diferentes âmbitos no interior dos quais os professores elaboram uma narrativa de sua profissão e uma visão de si mesmos.

Diante dessas elaborações, tanto García (2003) quanto Nóvoa (1995) e Almeida (1999) nos ajudam a situar as linhas gerais do conceito de 
desenvolvimento profissional no interior das definições do ser docente. É importante destacar que o desenvolvimento profissional, embora central, está articulado à dimensão do professor como pessoa e da instituição escolar como o lugar onde dado exercício da profissão dar-se-á.

Aquilo que permeia os contextos de ensino marca as formas do desenvolvimento profissional, o que faz com que só se possa pensá-lo em sua relação com certa profissionalidade, que envolve as qualidades da prática profissional dos professores, definidas segundo a especificidade do ensinar (SACRISTÁN, 1995; ROLDÃO, 2007; CONTRERAS, 2012). Consideradas as políticas públicas docentes e as consequências que geram na orientação das práticas, entendemos o desenvolvimento profissional marcado não só e absolutamente pela formação, mas também pela estrutura e o arranjo institucional das políticas que apontam para concepções diversas sobre o trabalho docente e sua profissionalidade (GHEDIN; ALMEIDA; LEITE, 2007).

Isso aponta para a complexidade do desenvolvimento profissional, que, segundo García (2003), envolve não só outros desenvolvimentos (da escola e da profissionalidade, por exemplo), mas também uma série de concepções que respondem às propostas que atendem por nomenclaturas como aperfeiçoamento, treinamento e/ou formação em serviço. Para o autor espanhol, a expressão desenvolvimento profissional é guardada para se referir a uma abordagem da formação orientada para a mudança, mas que considera o caráter contextual e também organizacional desse processo formativo (GARCÍA, 2003, p. 137).

Nesse contexto alargado, em atenção também à formação, o desenvolvimento profissional passa a ser por excelência uma categoria que remete a uma trajetória na profissão, sendo assim uma espécie de categoria histórica. Essa trajetória teria como finalidade a conquista progressiva de maior autonomia e controle sobre o trabalho pelos professores, legitimada por uma competência profissional socialmente reconhecida. 
Em nossa leitura dos referenciais acima, como tentativa de síntese, compreendemos o desenvolvimento profissional dos professores como "um processo a longo prazo" (GARCÍA, 2009) que envolve a trajetória docente em seu processo de socialização profissional, na permanente aprendizagem e exercício da docência, possuindo uma orientação para a emancipação porquanto está comprometido com o desenvolvimento de um trabalho docente crítico e reflexivo. Do ponto de vista de sua relação com o mundo empírico, o desenvolvimento profissional tem por base o trabalho docente efetivamente realizado e envolve a identidade do professor, sua pessoa, seus valores e a complexidade organizacional que configura as condições concretas do próprio ensino.

\section{O trabalho docente como elemento articulador do fazer profissional dos professores}

Em nossa pesquisa, assumimos o caráter de centralidade do trabalho em sua dimensão ontológica e fundadora do ser social (ANTUNES, 2000, 2003; MARX, 2013). Sabemos que a atividade docente, embora dela não se possa dizer que seja um trabalho produtivo no sentido do paradigma econômico da produção de bens e mercadorias, tem a sua materialidade como processo de trabalho e dispêndio de energia. Para o materialismo histórico, o trabalho é a atividade humana de transformação da natureza e construção do mundo histórico. É atividade consciente orientada para um fim, investimento humano com sentido. Para essa perspectiva, o trabalho, tal como ontologicamente constituído, é a essência do homem, sendo a base de sua existência e de suas relações. Em formulação original, Marx (2013) o caracteriza como "[...] um processo entre o homem e a natureza" no qual o homem modifica "sua própria natureza” (MARX, 2013, p. 255).

O sentido do trabalho é humano, é atividade de "fabricação", de produção de objetos que, uma vez postos no mundo, são resultado e 
expressão das relações sociais que o produziram. O engendramento do homem pelo trabalho é a forma material de sua exteriorização, sua subjetividade objetivada. Portanto, o mundo construído é um mundo também social, produto de relações. Com esse ponto de partida, o trabalho é a determinação de um modo de vida.

Pensando na atividade educativa, acompanhamos Oliveira (2010), que define o trabalho docente "como todo ato de realização no processo educativo" e possui um caráter educativo inerente. Isso se relaciona com o interesse analítico de Duarte (2011) que, examinando o trabalho docente no contexto das reformas neoliberais, o concebe como tendo uma identidade específica não só do ponto de vista de sua regulação formal, mas também de sua natureza enquanto atividade orientada para um fim.

Tal compreensão se ampara no pressuposto de que "o trabalho docente é parte da totalidade constituída pelo trabalho no capitalismo, estando submetido, portanto, à sua lógica e às suas contradições" (DUARTE, 2011, p. 163). É nessa sociedade que o trabalho dos professores se insere. Isso faz com que aquilo que se espera de sua formação (inicial ou continuada) esteja atravessado pelas demandas dessa mesma sociedade.

Como parte dessa construção conceitual do trabalho docente entendido como práxis, reproduzimos os pressupostos para esse conceito apresentados por Azzi (2009, p. 38):

- o trabalho docente é uma práxis em que a unidade teoria e prática se caracteriza pela ação-reflexão-ação;

- o trabalho docente só pode ser compreendido se considerado no contexto da organização escolar e da organização do trabalho no modo de produção, no caso, capitalista;

- a compreensão do trabalho docente só pode ocorrer no processo de elaboração de seu conceito, que emerge após o estudo de sua gênese, de suas condições históricas gerais (o trabalho como forma histórica) e particulares (o cotidiano da ação docente (AZZI, 2009, p. 38). 
Importa salientar, ademais, que o trabalho docente se realiza em torno de uma prática, a qual possui estatutos distintos conforme sua determinação (FRANCO, 2012). Ele possui, no mínimo, dois componentes: por um lado, ele possui um componente individual, ligado à mobilização de modos de fazer únicos, singulares, e, por outro, possui uma dimensão de ordem estrutural, organizada segundo modos de fazer que se sedimentam e constituem a "forma de ser" de determinada coletividade (SACRISTÁN, 1999).

É aí, nesse entrecruzamento, que podemos posicionar nossa atenção para entender as orientações de ação dos professores e que sentido sua ação (sociopedagógica) possui para si. Como o professor concebe seu trabalho, e como produz seus modos próprios de alienação ou emancipação, precisa ser visto lá onde o indivíduo e a coletividade se encontram, se negam e se refazem.

\section{Formação continuada como articulação entre desenvolvimento profissional e trabalho docente}

$\mathrm{Na}$ articulação entre o trabalho e o desenvolvimento profissional, nosso entendimento na pesquisa é o de que a formação continuada é o elemento que permite as conexões entre as práticas que efetivam o trabalho e a trajetória no interior da qual o ser social docente se constitui. Esta é afinal nossa hipótese de trabalho na proposição conceitual: o lugar $d a$ formação continuada é o da interação com o trabalho docente como ação que inclui, mas não encerra, o desenvolvimento profissional.

Com base em Nóvoa (1995), afirmamos que a prática profissional se dá na confluência da pessoa, da instituição, dos sistemas e dos saberes profissionais que permitem a mobilização efetiva para o conhecimento no interior da escola. A complexidade que envolve a formação do professor em exercício da docência não pode ser negligenciada, sob pena de perdermos o 
foco do elemento central a partir do qual o profissional constrói sua identidade e sua relação com a profissão, qual seja, o trabalho como categoria ontológica. Logo, a formação continuada precisa ser contextualizada e atenta às dinâmicas por meio das quais os professores produzem seu lugar na profissão e na sociedade.

Apesar dos avanços nesse campo, o contexto geral mostra que, em nosso tempo, a formação de caráter permanente tem se tornado obrigação aos professores, não mais entendida nem como direito, nem como necessidade (NÓVOA, 2009). Com isso, perde-se o sentido profundo da formação ao longo da vida como componente do desenvolvimento pessoal e profissional, e tal caráter de compulsoriedade passa a destituir os professores da possibilidade de constituição humana, reduzindo-se sua participação à presença física nos espaços e não ao desenvolvimento de si e de sua profissionalidade. As tendências de renovação da formação já se faziam sentir desde a década de 1990, propondo-se, em âmbito internacional, a reflexão sobre a prática, a necessidade de reforma da escola, o trabalho colegiado/coletivo entre docentes e outros dispositivos ainda muito importantes nos tempos que correm (TORRES, 1998).

Por nosso turno, concebemos que a formação continuada constitui uma dimensão da reflexão do professor sobre seu trabalho que fortalece a profissionalidade construída de dentro da profissão (NÓVOA, 2009), não sendo o professor um observador ou receptáculo dos saberes profissionais (transmitidos ou trabalhados em um curso), mas sim um agente construtor de sua profissão enquanto vivencia as ações produtoras de seu desenvolvimento profissional.

Diante disso, a formação continuada, como parte do desenvolvimento profissional dos professores, é um elemento potente para a (re)configuração de sua profissionalidade, por trazer para as ações dos cursos e encontros a reflexão situada sobre o trabalho do professor. Sua tarefa política é contribuir para o avanço da profissionalização dos professores mediante programas sistemáticos que privilegiem a autonomia dos docentes em sua 
prática, tornando-se uma exigência para o desenvolvimento profissional dos professores na contemporaneidade.

Por fim, dada a centralidade do trabalho docente, salientamos a relevância de compreender a formação contínua como parte do desenvolvimento profissional por três razões: 1) a formação é um elemento constitutivo da profissionalização permanente dos professores; 2) a formação, nos termos aqui enfocados, concebe os professores como profissionais; 3) a formação permite a superação de uma visão do professor como um mero prático que, embora reflexivo, opera a partir de uma pobre racionalidade instrumental.

Essas razões se apresentam como linhas de força com destacado papel para a formulação das políticas de formação docente e para a reconfiguração da profissionalidade dos professores nos contextos de atuação. Elas também demandam a consideração das condições de trabalho e da estruturação da carreira que formam a estrutura no interior da qual eles atuam.

\section{Conclusão}

Neste texto procuramos situar alguns aspectos da complexidade que envolve o desenvolvimento profissional dos professores. Empreendemos esse esforço pela consideração do lugar da formação continuada e do trabalho docente em sua configuração. Nosso argumento de base é o de que o desenvolvimento profissional é marcado pelas condições concretas da prática profissional docente. No âmbito propositivo das políticas públicas, é a formação continuada que pode se constituir como elemento de articulação da totalidade que envolve a atuação dos professores.

Repondo os argumentos expostos, salientamos, de modo geral, ser o desenvolvimento profissional um continuum que perpassa a constituição geral do ser docente, configurando e dando sentido à formação continuada em sua relação com o trabalho realizado. Nessa dialética, concebemos como 
fundamental a articulação entre a trajetória do professor (o desenvolvimento profissional como "filme") e os momentos significativos de sua consecução (a formação contínua como "fotografia").

Ademais, salientamos a pertinência de conceber a centralidade do trabalho como categoria dialética que envolve a condição docente no interior de uma totalidade social. A amplitude do conceito fornece o esteio para uma análise do trabalho realizado pelos professores, sua relação com a profissionalização (formação) e de que modo se operam as formas de realização ou estranhamento em sua atividade social e pedagógica.

Toda reconstrução teórica aqui proposta, que é parte de um movimento argumentativo mais amplo e denso, tem como pano de fundo o projeto emancipatório que concebe os professores como sujeitos de seu trabalho. Em nossa leitura, dominando os instrumentos de conhecimento para a realização do seu trabalho, o professor emerge como um intelectual crítico-reflexivo. Ele é "sujeito de seu trabalho e não pode, por isso mesmo, ser tomado como objeto de determinações que lhe chegam de fora para dentro ou de cima para baixo" (SILVA JUNIOR, 2015, p. 123). Daí a necessidade de construirmos a profissão e o espaço público de sua formação como esfera de uma voz que se configura como um lugar de fala próprio e socialmente reconhecido, seja na esfera educacional mais imediata, seja na esfera política mais ampla.

\section{Referências}

ALARCÃO, Isabel. Professores reflexivos em uma escola reflexiva. São Paulo: Cortez, 2003.

ALMEIDA, Maria Isabel de. O sindicato como instância formadora dos professores: novas contribuições ao desenvolvimento profissional. 1999. Tese (Doutorado em Educação) - Faculdade de Educação, Universidade de São Paulo, São Paulo, 1999.

; GHEDIN, Evandro; LEITE, Yoshie Ussami Ferrari. Formação de professores: caminhos e descaminhos da prática. Brasília: Líber Livro Editora, 2008. 
ANDRÉ, Marli Eliza Dalmazo Afonso de. Formação de professores no Brasil (19901998). Brasília-DF: MEC/Inep/Comped, 2002.

. Pesquisa em educação: buscando rigor e qualidade. Cadernos de Pesquisa, São Paulo, n. 113, p. 51-64, jul. 2001.

ANTUNES, Ricardo. Adeus ao trabalho?: ensaio sobre as metamorfoses e a centralidade do mundo do trabalho. 9. ed. São Paulo: Cortez; Campinas, SP: Editora da Unicamp, 2003.

Os sentidos do trabalho: ensaio sobre a afirmação e a negação do trabalho. 2. ed. São Paulo: Boitempo, 2000.

AZZI, Sandra. Trabalho docente: autonomia didática e construção dos saberes da docência. In: PIMENTA, Selma Garrido (Org.). Saberes pedagógicos e atividade docente. 7. ed. São Paulo: Cortez, 2009.

BRZEZINSKI, Iria. Formação de profissionais da educação (2003-2010). Brasília: Inep, 2014.

MEC/Inep, 2006.

CONTRERAS, José. Autonomia de professores. 2. ed. Trad. Sandra Trabucco Venezuela. São Paulo: Cortez, 2012.

DAY, Christopher. Desenvolvimento profissional de professores: os desafios da aprendizagem permanente. Trad. Maria Assunção Flores. Porto: Porto Editora, 2001.

DINIZ-PEREIRA, Júlio Emílio. A construção do campo da pesquisa sobre formação de professores. Revista da FAEEBA - Educação e Contemporaneidade, Salvador, v. 22, n. 40, p. 145-154, jul./dez. 2013.

Formação continuada de professores. In: OLIVEIRA, Dalila Andrade; DUARTE, Adriana Maria Cancella; VIEIRA, Lívia Maria Fraga. Dicionário: trabalho, profissão e condição docente. Belo Horizonte: UFMG/Faculdade de Educação, 2010.

DUARTE, Adriana. Políticas educacionais e o trabalho docente na atualidade: tendências e contradições. In: ; OLIVEIRA, Dalila Andrade (Org.). Políticas públicas e educação: regulação e conhecimento. Belo Horizonte, MG: Fino Traço, 2011.

FRANCO, Maria Amélia Santoro. Práticas Pedagógicas nas múltiplas redes educativas. In: LIBANEO, José Carlos; ALVES, Nilda (Orgs.). Temas de Pedagogia: diálogos entre didática e currículo. São Paulo: Cortez, 2012. 
FUNDAÇÃO CARLOS CHAGAS. Formação continuada de professores: uma análise das modalidades e das práticas em estados e municípios brasileiros. São Paulo: FCC, [s. d.].

FUSARI, José Cerchi. Formação contínua de educadores: um estudo de representações de coordenadores pedagógicos da Secretaria Municipal de Educação de São Paulo (SMESP). 1997. Tese (Doutorado em Educação) - Faculdade de Educação, Universidade de São Paulo, São Paulo, 1997.

GARCÍA, Carlos Marcelo. Desenvolvimento profissional docente: passado e futuro. Sísifo. Revista de Ciências da Educação, Lisboa, n. 8, p. 7-22, jan./abr. 2009.

Desenvolvimento profissional dos professores. In: Formação de professores: para uma mudança educativa. Porto: Porto Editora, 2003.

IMBERNÓN, Francisco. Formação docente e profissional: formar-se para a mudança e a incerteza. 4. ed. São Paulo: Cortez, 2004.

KOSIK, Karel. Dialética do concreto. Rio de Janeiro: Paz e Terra, 1969.

LIMA, Maria Socorro Lucena. A formação dos professores nos caminhos $e$ descaminhos do desenvolvimento profissional. 2001. Tese (Doutorado em Educação) - Faculdade de Educação, Universidade de São Paulo, São Paulo, 2001.

MARX, Karl. O Capital: crítica da economia política: Livro I: o processo de produção do capital. Trad. Rubens Enderle. São Paulo: Boitempo, 2013.

MELO, Rúrion Soares. Sentidos da emancipação: para além da antinomia revolução versus reforma. 2009. Tese (Doutorado em Filosofia) - Faculdade de Filosofia, Letras e Ciências Humanas, Universidade de São Paulo, São Paulo, 2009.

MORGADO, José Carlos. Identidade e profissionalidade docente: sentidos e impossibilidades. Ensaio: Avaliação e Políticas Públicas em Educação, Rio de Janeiro, v. 19, n. 73, p. 793-812, out./dez. 2011.

NÓVOA, António. Professores: imagens do futuro presente. Lisboa: EDUCA, 2009.

Vidas de professores. 2. ed. Portugal: Porto, 2000.

. Os Professores na virada do milênio: do excesso dos discursos à pobreza das práticas. Educação e Pesquisa, São Paulo, v. 25, n. 1, p. 11-20, jan./jun. 1999.

Formação de professores e profissão docente. In: NÓVOA, António (Org.). Os professores e a sua formação. Lisboa: Publicações Dom Quixote, 1995.

OLIVEIRA, Dalila Andrade. Trabalho docente. In: ; DUARTE, Adriana Maria Cancella; VIEIRA, Lívia Maria Fraga. Dicionário: trabalho, profissão e condição docente. Belo Horizonte: UFMG/Faculdade de Educação, 2010. 
PIMENTA, Selma Garrido. Epistemologia da prática: ressignificando a didática. Disponível em: <http://www.ufmt.br/endipe2016/epistemologia-da-praticaressignificando-a-didatica/>. Acesso em: $13 \mathrm{dez} .2016$.

. Formação de professores: identidade e saberes da docência. In:

(Org.). Saberes pedagógicos e atividade docente. 7. ed. São Paulo: Cortez, 2009.

SACRISTÁN, José Gimeno. Poderes instáveis em educação. Trad. Beatriz Affonso Neves. Porto Alegre: Artes Médicas Sul, 1999.

- Consciência e acção sobre a prática como libertação profissional dos professores. In: NÓVOA, António (Org.). Profissão professor. 2. ed. Porto: Porto Editora, 1995.

ROLDÃO, Maria do Céu. Função docente: natureza e construção do conhecimento profissional. Revista Brasileira de Educação, Rio de Janeiro, v. 12, n. 34, p. 94-181, jan./abr. 2007.

SCHÖN, Donald. Formar professores como profissionais reflexivos. In: NÓVOA, António (Org.). Os professores e a sua formação. Lisboa: Publicações Dom Quixote, 1995.

SILVA JUNIOR, Celestino Alves da. Construção de um espaço público de formação. In: GATTI, Bernadete Angelina et al. Por uma revolução no campo da formação de professores. São Paulo: Editora Unesp, 2015.

TANURI, Leonor Maria. História da formação de professores. Revista Brasileira de Educação, Rio de Janeiro, n. 14, p. 61-88, mai./jun./jul./ago. 2000.

TARDIF, Maurice. Saberes docentes e formação profissional. Rio de Janeiro: Petrópolis: Vozes, 2002.

TORRES, Rosa Maria. Tendências da formação docente nos anos 90. In: WARDE, Mirian Jorge (Org.). Novas políticas educacionais: críticas e perspectivas. São Paulo: Programa de Estudos Pós-Graduados em Educação: História e Filosofia da Educação da Pontifícia Universidade Católica de São Paulo, 1998. 